\title{
Epidemiology and Implications of Ocular Trauma Admitted to a Tertiary Care Hospital in North India
}

Kirti Singh, Ankush Mutreja, Mainak Bhattacharyya, and Sonal Dangda

Guru Nanak Eye Centre, Delhi, India

DOI: https://doi.org/10.17925/USOR.2017.10.01.64

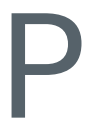

urpose: To study the aetiology, epidemiological profile of patients presenting with ocular trauma and compare visual outcomes of early versus late presentatiod. Design: Prospective observational study performed over fifteen month interval. Methods: Patients' epidemiological characteristics were evaluated along with cause of trauma, place of injury, time lag post injury, and postoperative management. Injuries were classified by Birmingham Eye Trauma Terminology (BETT). Final visual and anatomical outcome after providing tailored surgical management was evaluated. All patients had a minimum follow up of 6 months. Statistical Analysis: All the data collected was analysed using SPSS version 17.0 software. Results: One hundred and three cases of incident ocular injury were included in the study. Open globe: closed globe injuries were $78: 22 \%$ respectively with intraocular foreign body present in $9 \%$ of cases. Actively working adults younger than 25 years of age were the commonest age group affected (64\%). The commonest place of injury was at home (32\%) followed by workplace environment (29\%). Good outcome (vision of $>6 / 60$ Snellen) could be achieved in $50 \%$ cases, of which $53 \%$ had purely anterior segment injury and $20 \%$ concomitant retinal injury. Good outcome had a direct correlation with early presentation in $57 \%$ and poor outcome with late presentation seen in $64 \%$ cases. Conclusion: Serious ocular trauma frequently occurs at home with the younger population maximum at risk. Good visual acuity is associated with early intervention and purely anterior segment injuries.

\section{Keywords}

Epidemiology, ocular trauma, injury, intraocular foreign body, visual outcome

Disclosure: Kirti Singh, Ankush Mutreja, Mainak Bhattacharyya, and Sonal Dangda have no conflicts of interest to declare. No funding was received in the publication of this article.

Compliance with Ethics: All procedures were followed in accordance with the responsible committee on human experimentation and with the Helsinki Declaration of 1975 and subsequent revisions.

Authorship: All named authors meet the International Committee of Medical Journal Editors (ICMJE) criteria for authorship of this manuscript, take responsibility for the integrity of the work as a whole, and have given final approval to the version to be published.

open Access: This article is published under the Creative Commons Attribution Noncommercial License, which permits any noncommercial use, distribution, adaptation, and reproduction provided the original author(s) and source are given appropriate credit.

Received: October 26, 2017

Accepted: February 6, 2017

Citation: US Ophthalmic Review , 2017:10(1):64-8

Corresponding Author: Mainak Bhattacharyya, Guru Nanak Eye Centre, Maharaja Ranjit Singh Marg Delhi -110002, India. E: drmainakb@gmail.com
Ocular trauma is an important worldwide cause of preventable morbidity and accounts for half a million cases of monocular blindness worldwide. ${ }^{1-5}$ Paucity of epidemiological data regarding ocular trauma in the developing world is a major factor in implementing effective health policy measures.

The only national estimate regarding the Indian subcontinent is from a survey conducted from 1971-1974, where ocular trauma accounted for $1.2 \%$ of national blindness. ${ }^{6}$ An ideal data collection system for ocular injury should incorporate population-based comparisons using a known denominator; demographic data, details of injury, visual acuity (VA) at presentation and final outcome after appropriate management.? Factors that have been found to correlate significantly with visual outcome post ocular trauma include age, ${ }_{1}^{8}$ type or mechanism of injury, ${ }_{1}^{2,9-13}$ initial VA, ${ }^{2,11-13}$ presence of relative afferent pupillary defect (RAPD), ${ }^{8,11-14}$ extent of wound and size of open globe injury, ${ }_{1}^{2,11-13}$ location of open globe wound, ,,10-13 lens damage, ,,11-13 hyphema, 11,13,15 vitreous hemorrhage, 2,11,13,15-16 retinal detachment, ${ }^{17}$ and presence and type of intraocular foreign body (IOFB). ${ }^{18}$ This study was conducted keeping these parameters in mind and assessing the requisite denominators.

\section{Materials and methods}

This study was a prospective observational study of all patients admitted to a tertiary hospital with ocular trauma between December 2012 and March 2014.

\section{Inclusion/exclusion criteria}

since this was an epidemiological study, all patients irrespective of their age, mode of injury, time since injury, presenting VA, reporting to the emergency services of the hospital were included in the study after the requisite consent to be a part of the study and willingness for follow up.

Data collected were demographic profile, type and mode of injury, first aid received, complete ophthalmic evaluation including appropriate investigations (X-ray Orbit, Ultrasonography, computed tomography [CT] scan wherever applicable). All patients were graded from A-E based on presenting VA as per Birmingham Eye Trauma Terminology (BETT)..$^{19}$ The zone of injury was graded from II-III 
for open as well as closed globe injuries. Ocular Trauma Scoring System (OTSS) was computed to assess the prognosis of final visual outcome of the patient.. ${ }^{20}$ All patients with vision equal to or worse than grade $\mathrm{D}$, zone II and III injuries, hyphema on initial presentation, subluxated lens, RAPD, IOFB, vitreous hemorrhage, retinal detachment, and endophthalmitis at presentation were classified as "severe" injuries. For injuries with multiple diagnoses, those with a "severe" component were categorized as severe. ${ }^{4}$

All patients were managed as per standard management protocol, whether surgical or medical, followed by appropriate medical management. Ultrasound was conducted after 48 hours of surgical intervention whenever preoperative ultrasound had not been performed. This was to confirm or exclude posterior segment involvement. Secondary intervention like cataract extraction, IOFB removal and retinal detachment surgery were planned and performed at appropriate time intervals.

All patients were followed up for 6 months and evaluated for VA (near and distance), inflammation (anterior segment or retrolental) in both the injured and non-injured eyes. The latter was done, keeping in mind the propensity of sympathetic ophthalmitis and assess requirement of any further intervention in both the injured and normal eye. All patients received two broad-spectrum systemic antibiotics for at least 7 days, two topical fortified antibiotics (vancomycin plus ceftazidime or cephazolin plus tobramycin) for at least 6 weeks after the injury. Oral steroids were administered in cases with potential risk of sympathetic ophthalmitis (ciliary body injury, mutilating iris trauma, non-infected perforations). VA $\geq 6 / 60$ was defined as "good" vision post intervention (Grade A and B).

All the procedures followed were in accordance with the ethical standards of the responsible committee on human experimentation (institutional or regional) and with the Helsinki Declaration of 1975, revised in 2000.

All the data collected were analyzed using SPSS version 17.0 software. Routine statistics, including means, proportions and chi-square tests were carried out. Odds ratio (OR) and 95\% confidence intervals (Cl) were computed to evaluate the strength of association between various factors.

\section{Results}

A total of 103 patients were evaluated for the duration of study over a period of 15 months. All patients were followed up for a minimum of 6 months.

\section{Demographics}

Most patients (64\%) were younger than 25 years of age and most injuries (71\%) were unrelated to work or the patient's occupation (see Table 1).

\section{Initial clinical presentation}

Seventy-six patients had poor VA of Grade D or E on initial presentation. The proportion of open globe to closed globe injury was 78:22; $77.5 \%$ open globe injuries being penetrating. Seventeen patients had globe rupture and one patient had globe perforation. Injury grade was zone I in 43 patients, zone II and III injuries in 34 and three patients, respectively (see Table 2). In 23 patients with closed globe injury, nine had injuries confined to zone I, seven each to zone II and zone III. The mean OTSS score was 46.27.

Imaging (X-ray orbit) revealed intra-ocular foreign body in nine (8.7\%) cases, or $11 \%$ of all open globe injuries. In the entire series, 82 (80\%) patients were categorized as having "severe" ocular trauma.
Table 1: Patient profile

\begin{tabular}{|c|c|}
\hline \multicolumn{2}{|l|}{ Age (in years) } \\
\hline $\begin{array}{l}<15 \\
16-25 \\
26-55 \\
>55\end{array}$ & $\begin{array}{l}40 \\
26 \\
23 \\
14\end{array}$ \\
\hline \multicolumn{2}{|l|}{ Sex } \\
\hline $\begin{array}{l}\text { Male } \\
\text { Female }\end{array}$ & $\begin{array}{l}80 \\
23\end{array}$ \\
\hline \multicolumn{2}{|l|}{ Place of injury } \\
\hline Home & 33 \\
\hline $\begin{array}{l}\text { Domestic worker } \\
\text { Children at home } \\
\text { Infants and pre-school children }\end{array}$ & $\begin{array}{l}7 \\
11 \\
15\end{array}$ \\
\hline Workplace & 30 \\
\hline $\begin{array}{l}\text { Factory worker } \\
\text { Farmer } \\
\text { Ironsmith } \\
\text { Fisherman } \\
\text { Electrician } \\
\text { Self-employed } \\
\text { Driver }\end{array}$ & $\begin{array}{l}17 \\
3 \\
1 \\
1 \\
1 \\
4 \\
3\end{array}$ \\
\hline Unrelated to work and home & 26 \\
\hline $\begin{array}{l}\text { Children } \\
\text { Infants and pre-school children } \\
\text { Festival-related }\end{array}$ & $\begin{array}{l}18 \\
8 \\
14\end{array}$ \\
\hline \multicolumn{2}{|l|}{ Occupation } \\
\hline \multicolumn{2}{|l|}{ Mode of injury } \\
\hline $\begin{array}{l}\text { Metallic } \\
\text { Iron rod } \\
\text { Nail } \\
\text { Non-metallic } \\
\text { Glass } \\
\text { Wood } \\
\text { Stone } \\
\text { Others } \\
\text { Pen } \\
\text { Assault } \\
\text { Road traffic accident } \\
\text { Fire-cracker } \\
\text { Unknown }\end{array}$ & $\begin{array}{l}32 \\
30 \\
2 \\
39 \\
7 \\
25 \\
7 \\
32 \\
2 \\
7 \\
6 \\
6 \\
11\end{array}$ \\
\hline \multicolumn{2}{|l|}{ Catchment area } \\
\hline $\begin{array}{l}\text { Delhi } \\
\text { Outside Delhi } \\
\text { Uttar Pradesh } \\
\text { Bihar } \\
\text { Haryana } \\
\text { Punjab }\end{array}$ & $\begin{array}{l}61 \\
42 \\
21 \\
6 \\
7 \\
5\end{array}$ \\
\hline
\end{tabular}

Ultrasonography performed either at presentation or 48 hours after initial repair for posterior segment evaluation documented vitreous hemorrhage and retinal detachment in 20 and 16 patients respectively. Endophthalmitis occurred in five cases of penetrating trauma out of 103 patients (5\%). Ninetytwo cases (89\%) had some form of anterior segment trauma whereas 60 patients (58\%) had posterior segment trauma singly or in combination with anterior segment injuries (see Table 3). 
Table 2: Type of injury and presentation

\begin{tabular}{|l|l|}
\hline $\begin{array}{l}\text { Type of injury } \\
\text { Open globe }\end{array}$ & $80(78 \%)$ \\
\hline Type & $62(60 \%)$ \\
\hline Penetrating & $18(17 \%)$ \\
\hline Rupture & $1(1 \%)$ \\
\hline Perforation & \\
\hline Zone & 43 \\
\hline I & 34 \\
\hline II & 3 \\
\hline III & $23(22 \%)$ \\
\hline Closed globe & $19(18 \%)$ \\
\hline Blunt & $2(2 \%)$ \\
\hline Chemical & $2(2 \%)$ \\
\hline Lid laceration & \\
\hline Zone & 7 \\
\hline I & 9 \\
\hline II & 7 \\
\hline III & \\
\hline Time since presentation & 29 \\
\hline$<6$ hours & 38 \\
\hline $6-48$ hours & 15 \\
\hline $2-7$ days & 6 \\
\hline $7-14$ days & 15 \\
\hline$>14$ days & \\
\hline
\end{tabular}

Table 3: Prognosticators

\begin{tabular}{|l|l|l|}
\hline \multirow{2}{*}{ Anterior chamber } & Hyphema & 27 \\
& Hypopyon & 5 \\
\hline \multirow{2}{*}{ Pupil } & Subluxation/Dislocation & 8 \\
\hline & Cataract & 20 \\
\hline & Mydriasis & 8 \\
\hline & RAPD & 3 \\
\hline & Sluggishly reacting & 16 \\
\hline & Fixed & 25 \\
\hline & Details not visible & 51 \\
\hline Posterior segment & Vitreous hemorrhage & 20 \\
\hline & Retinal detachment & 16 \\
\hline Foreign body & 9 \\
\hline & Endophthalmitis & 5 \\
\hline
\end{tabular}

$R A P D=$ relative afferent pupillary defect

\section{Follow-up}

All patients were followed up for a minimum period of 6 months. VA at the end of 6 months was recorded and graded from $A$ to $E$ as per grading of presenting VA (see Figure 1).

Good visual outcome was attained in 52 cases (50.4\%), of which 48 patients had anterior segment injury and 12 had either posterior segment injury alone or along with anterior segment injury. In the subgroup of patients with
Figure 1: Grade of ocular trauma

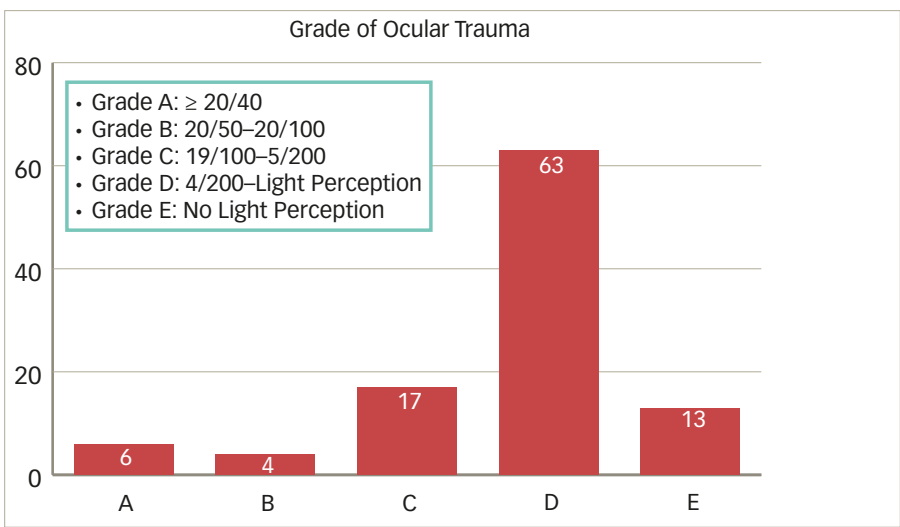

Figure 2: A patient with past history of radial keratotomy with corneal rupture due to blunt trauma, subsequently, corneal suturing was done

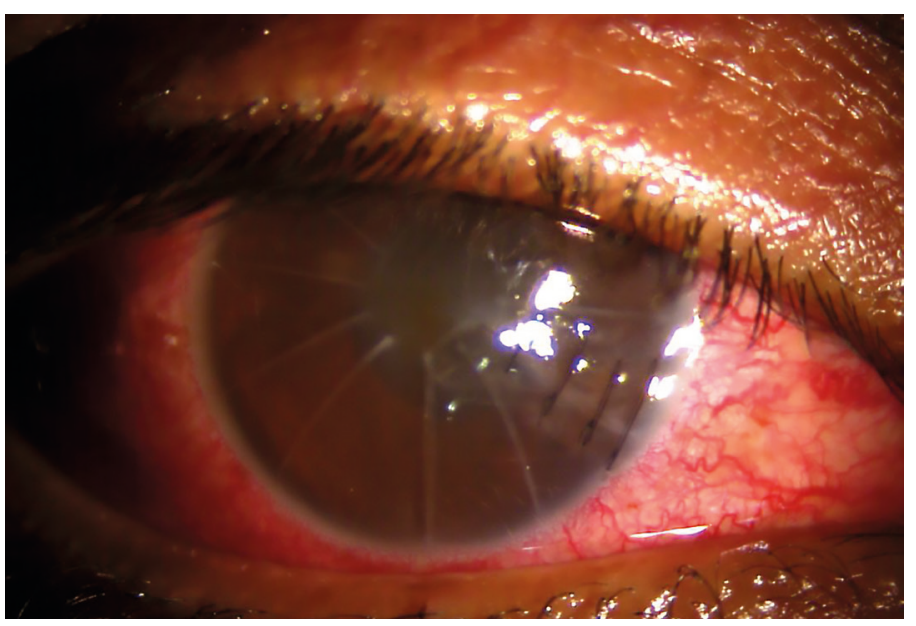

Figure 3: Fifty-four-year old male with 10-day old history of injury with glass splinter in left eye; on examination denied light perpection. The eye was subsequently eviscerated

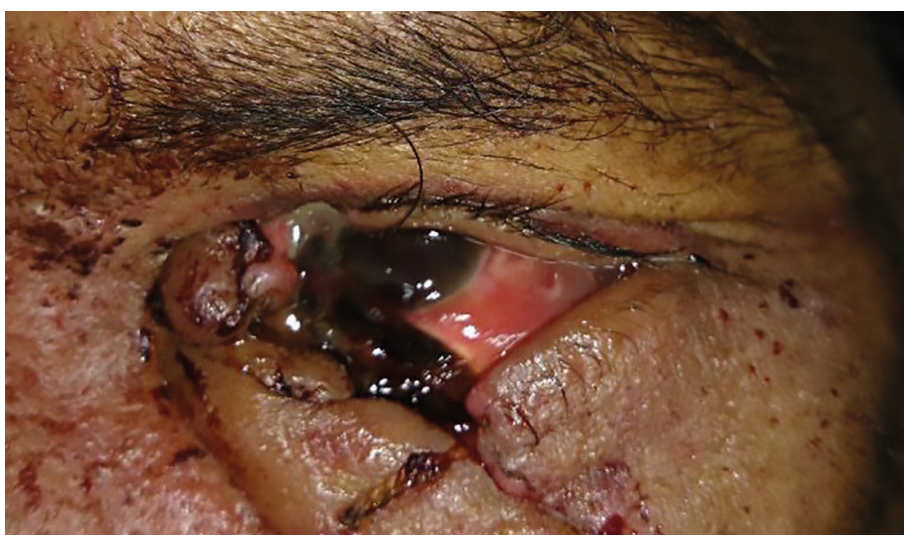

good visual outcome, $56 \%$ presented within 48 hours of injury. In those with poor outcome (final vision $<6 / 60$ ), late presentation beyond 48 hours was seen in $41.2 \%$ cases (see Table 4). 


\section{Discussion}

This prospective, hospital-based study provides data on the current pattern of serious ocular injuries in patients admitted to a tertiary care center in the emergency department.

Most of the patients who sought healthcare for ocular trauma were males (78\%). This could be explained by the health-seeking behavior of the population studied, where males are given preferential treatment. Previous studies have highlighted this aspect citing increased vulnerability of male gender in being exposed to outdoor work activities in agriculture and industry ${ }^{10-11,19-22}$ However, this does not particularly hold true for our study, where home-related injuries predominated.

Children and young adults were commonest age group to be afflicted, because of their adventurous activities and treatment being sought more often, compared with the neglected elderly population. Studies from both developed and developing worlds have confirmed this aspect of ocular trauma. ${ }^{1-3,5,25}$ The restricted mobility of the elderly leading to inability in accessing medical facilities situated at distances could be another reason for this disproportionate statistic. A significant proportion of patients (42 of 103) had travelled from neighboring states to avail themselves of adequate and economically viable treatment facilities. This reflects the large catchment area and inadequate access to tertiary hospitals providing subsidized treatments. The high proportion of "serious" ocular trauma observed in this study at $80 \%$ could be due to weeding out of less serious cases treated at peripheral healthcare facilities.

The study revealed that the most injuries occurred at home and lack of basic safety precautions was the common factor. This is at variance with previous studies reporting work related injuries to be more common. ${ }^{4,26-30}$ These findings have implications for health and safety strategies in prevention of serious eye injuries. The current emphasis on safe work environments must be expanded to include the home environment. Inculcating awareness of hazardous activities involving domestic tools and use of specific protective eye wear needs to be highlighted. It is likely that the magnitude of domestic ocular injuries is even greater and that the reported cases are just the tip of the iceberg.

A significant number of injuries (13\%) were festival-related, for example through bow-and-arrow-related injuries or fire-cracker-related injury during Dussehra and Diwali, festivals indigenous to our country. As most of these injuries occurred in children, it underscores a lack of awareness among parents about the hazards of leaving children unattended during these popular festivals. Many countries have used legislative measures to regulate the use of fireworks. ${ }^{31-32}$ Implementation of similar legislative measures would go a long way in reducing firework-related injuries in India. Apart from these regulations, legislation should stipulate all safety measures including the age limit for independently handling these devices, as well as the minimum distance that ought to be maintained while lighting firecrackers and watching fireworks. Children should handle firecrackers only under adult supervision and use protective eyewear while handling the firecrackers. ${ }^{33}$
Table 4: Visual outcome

\begin{tabular}{|l|l|}
\hline Good visual outcome & 52 \\
\hline Anterior segment & 48 \\
\hline Posterior segment & 44 \\
\hline Time of presentation (<48 hours) & 40 \\
\hline Time of presentation ( $>48$ hours) & 12 \\
\hline Poor visual outcome & 51 \\
\hline Anterior segment & 44 \\
\hline Posterior segment & 48 \\
\hline Time of presentation (<48 hours) & 30 \\
\hline Time of presentation ( $>48$ hours) & 21 \\
\hline
\end{tabular}

The reporting time of the majority (68\%) of patients was within 48 hours of injury, highlighting increased awareness among people to seek early medical intervention for ocular trauma. This reflects success of mass awareness campaigns initiated for preventing avoidable blindness.

Good visual outcome (final best corrected VA $26 / 60$ ), could be attained in 52 cases, of which 53\% had anterior segment injury alone and $20 \%$ had concomitant retinal injury. Chi-square values without Yates correction equaled 15.73 with one degree of freedom and two-tailed p-value $<0.0001$, make the association between anterior segment injury and visual outcome extremely significant. Patients with posterior segment injury, particularly those with intra-ocular foreign body (11\% of all open globe injuries) had more adverse visual outcome in view of increased incidence of vitreous hemorrhage, retinal detachment and endophthalmitis associated with it. (see Table 3). The cutoff of $6 / 60$ was taken, keeping in mind the definition of blindness to be $<6 / 60$ as per Indian National Programme for Control of Blindness (NPCB) guidelines. ${ }^{34}$

A determinant for good visual outcome was early presentation within 48 hours of injury; $57 \%$ patients with early presentation had good visual outcome (see Table 4). Conversely, poor outcome was associated with late presentation beyond 48 hours; seen in $64 \%$ cases with late presentation. Statistical test of Chi-square without Yates correction, equaled 3.87 with one degree of freedom found two-tailed p-value to be 0.049 , implying statistically significant correlation between early presentation and better visual prognosis. The statistical significance was, however, diluted due to confounders like early endophthalmitis and auto-evisceration, which had nil visual prognoses.

Ocular trauma in developing countries has not been studied extensively. This study in a developing country such as India underscores that trauma remains a significant cause of monocular vision loss in all age groups with a large proportion affecting younger patients, thereby entailing increased lifetime of disability years. The need for adoption of safe behavior in the home environment, which is traditionally envisaged as safe, use of protective eyewear to avoid most workplace-related injuries and early intervention are other aspects highlighted by this study. $\square$ 
1. Parver LM, Eye trauma: The neglected disorder, Arch Ophthalmol, 1986;104:1452

2. De Juan EJ, Sternberg PJ, Michels RG, Penetrating ocular injuries: Types of injuries and visual results, Ophthalmology, 1983;90:1318-22

3. Thylefors B, Epidemiological patterns of ocular trauma, Aust N Z J Ophthalmol, 1992;20:95-8.

4. Soliman MM, Macky TA, Pattern of ocular trauma in Egypt, Graefes Arch Clin Exp Ophthalmol, 2008; 246:205-12.

5. Khatry SK, Lewis AE, Schein OD, et al., The epidemiology of ocular trauma in rural Nepal, Br J Ophthalmol, 2004;88:456-60.

6. Indian Council of medical Research: collaborative study on blindness in India (1971-74). Available at: http://icmr.nic.in/ophicmr.pdf (accessed August 28, 2014).

7. Schein $\mathrm{OD}$, Hibberd $\mathrm{PL}$, Shingleton BJ, et al., The spectrum and burden of ocular injury, Ophthalmology, 1988;95:300-5.

8. Sternberg P Jr, de Juan E Jr, Michels RG, Auer C, Multivariat analysis of prognostic factors in penetrating ocular injuries, Am Ophthalm, 1984;98:467-72.

9. Esmaeli B, Elner SG, Schork A, Elner VM, Visual outcome and ocular survival after penetrating trauma: A clinicopathologic study, Ophthalmology, 1995:102:393-400.

10. Pieramici DJ, Mathew W, MacCumber, Humayun MU, Open globe injury: Update on types of injuries and visual results, Ophthalmology, 1996;103:1798-803.

11. Rao LG, Ninan A, Rao KA, Descriptive study on ocular survival, visual outcome and prognostic factors in open globe injuries, Indian J Ophthalmol, 2010;58:321-3.

12. Gupta A, Srinivasan R, Babu KR, Setia S, Comparison of the clinical presentation and visual outcome in open globe injuries in adults and children over 30 months, Eur J Ophthalmol, 2010;20:590-5.

13. Shah $\mathrm{M}$, Shah $\mathrm{S}$, Khandekar R, Ocular injuries and visual status before and after their management in the tribal areas of western
India: A historical cohort study, Graefes Arch Clin Exp Ophthalmol 2008;246:191-7

14. Rahman I, Maino A, Devadason D, Leatherbarrow B, Open globe injuries: factors predictive of poor outcome, Eye, 2006,20:133641.

15. Barr CC, Prognostic factors in corneoscleral laceration, Arch Ophthalmol, 1983;101:919-24.

16. Pieramici DJ, Au Eong K, Sternberg PJ, Marsh MJ, Prognostic significance of a system for classifying mechanical injuries of the eye (globe) in open globe injuries, J Trauma, 2003;54:790-4.

17. Gilber CM, Soong HK, Hirst LW, A two-year prospective study of penetrating ocular trauma at the Wilmer Ophthalmological Institute, Ann Ophthalmol, 1987:19:104-6.

18. Brinton $G S$, Aaberg TM, Reeser FH, et al., Surgical results in ocular trauma involving the posterior segment, Am J Ophthalmol 1982;93:271-8

19. Sahraravand A, Haavisto AK, Holopainen JM, Leivo T, Ocular traumas in working age adults in Finland - Helsinki Ocular Trauma Study, Acta Ophthalmol, 2016 Dec 9. doi: 10.1111/aos.13313.

20. Choragiewicz T, Nowomiejska K, Wertejuk K, et al., Surgical treatment of open globe trauma complicated with the presence of an intraocular foreign body, Klin Oczna, 2015;117(1):5e8

21. Jonas JB, Knorr HL, Budde WM, Prognostic factors in ocular injuries caused by intraocular or retrobulbar foreign bodies, Ophthalmology, 2000;107(5):823e8.

22. Kinderan YV, Shrestha E, Maharjan IM, Karmacharya S, Pattern of ocular trauma in the western region of Nepal, Nepal J Ophthalmol, 2012;4(1):5-9.

23. Kuhn $F$, Morris $R$, Witherspoon $C D$, Mester $V$, The Birmingham Eye Trauma Terminology system (BETT), J Fr Ophtalmol 2004;27(2):206-10

24. Kuhn F, Maisiak R, Mann L, et al., The ocular trauma score (OTS), Ophthalmol Clin North Am, 2002;15:163-5.
25. Cao H, Li L, Zhang M, Epidemiology of patients hospitalized for ocular trauma in the Chaoshan region of China, 2001-2010, PLOS One, 2012;7:e48377

26. Danneberg AL, Parver LM, Brechner RJ, Khoo L, Penetrating eye injuries in the work place. The national eye trauma system registry, Arch Ophthalmol, 1992;110:843-8.

27. Canavan YM, O'Flaherty MJ, Archer DB, Elwood JH, A 10-year survey of eye injuries in Northern Ireland, 1967-76, Br J Ophthalmol, 1980;64:618-25.

28. Batur M, Seven E, Esmer O, et al., Epidemiology of Adult Open Globe Injury, I Craniofac Surg, 2016;27:1636-41.

29. Yong GY, Pan SW, Humayun Akhter F, et al., Determinant Factors of Poor Visual Outcome After Ocular Trauma: A Retrospective Study in Central Sarawak, Malaysia, Asia Pac J Ophthalmol (Phila) 2016;5:137-42.

30. Loporchio D, Mukkamala L, Gorukanti K, et al., Intraocular foreign bodies: A review, Surv Ophthalmol, 2016;61:582-96.

31. Wilson RS, Ocular fireworks injuries and blindness. An analysis of 154 cases and a three-state survey comparing the effectiveness of model law regulation, Ophthalmology, 1982;89:291-7.

32. Chan WC, Knox FA, MCGinnity FG, Sharkey JA, Serious eye and adnexal injuries from fireworks in Northern Ireland before and after lifting of the firework ban - An ophthalmology unit's experience, Int Ophthalmol, 2004;25:167-9.

33. John D, Philip SS, Mittal R, et al., Spectrum of ocular firework injuries in children: A 5-year retrospective study during a festive season in Southern India, Indian J Ophthalmol, 2015;63:843-6.

34. Ministry of Social Justice and Empowerment. Guidelines for other disabilities. Notification dated 1 st June, 2001. The Gazette of India extraordinary. Part 1. Section 1. No 154. Available at: www.ccdisabilities.nic.in/page. php? $\mathrm{s}=$ regandt=defandf=printandp=guide_others $($ accessed December 11, 2014) 